\title{
How Poverty Alleviation Efforts Manifest among Smallholder Groundnut Farmers in Eastern Zambia
}

\author{
David T. Dillon ${ }^{1}$, Joshua A. Crosby ${ }^{1} \&$ Alyson G. Young ${ }^{2}$ \\ ${ }^{1}$ Department of Anthropology, University of Florida, Gainesville, FL, USA \\ ${ }^{2}$ Department of Health Outcomes \& Biomedical Informatics, University of Florida, Gainesville, FL, USA \\ Correspondence: David T. Dillon, University of Florida, Turlington Hall, Room 1112 PO Box 117305, Gainesville, \\ FL 32611-7305, USA. Tel: 1-336-829-8354. E-mail: davidtdillon@ufl.edu; david.thorne.dillon@gmail.com
}

Received: April 30, 2021

doi:10.5539/jsd.v14n3p184
Accepted: May 19, $2021 \quad$ Online Published: May 20, 2021

URL: https://doi.org/10.5539/jsd.v14n3p184

\begin{abstract}
Poverty alleviation and health promotion programs have become part and parcel of life in rural Zambia. It is critical to track the performance of these programs to assess the impact they have on the people involved. The purpose of this study is to ascertain barriers, specifically related to market access and crop yields, faced by smallholder groundnut farmers in Eastern Zambia following implementation of the PROFIT+ program. Focus group discussion and informants were selected based on participation in the PROFIT + . Interview data were then qualitatively analyzed to determine consistent themes among farmers. Farmers highlight three general barriers/risks that impacted both their economic well-being and health. In some cases, these barriers may act as feedback loops, health affecting economic productivity and vice versa. These include (a) a lack of adequate storage facilities (b) exposure to aflatoxins produced by the Aspergillus fungus (c) and exposure to pesticides due to a lack of personal protective equipment. Generally, groundnut farmers have benefitted from the efforts of PROFIT+, though challenges remain. Farmers consistently report increased their crop yields; however, access to outside markets has yet to materialize. Exposure to both aflatoxins and pesticides are concerning, particularly in areas of high stunting rates as these chemicals may exacerbate the effects of malnutrition. Further, changing weather patterns in the context of climate change increase issues faces by smallholder farmers.
\end{abstract}

Keywords: Zambia, farmers, Aflatoxins, pesticides, intervention

\section{Introduction}

Many poverty reduction efforts in sub-Saharan Africa focus on reducing the price of staple foods by introducing subsidies and boosting agricultural productivity (Alene \& Coulibaly, 2009; Jayne \& Rashid, 2013). Zambia is no exception, with more than $90 \%$ of funding for poverty reduction allocated by the Government of the Republic of Zambia (GRZ) for the Food Reserve Agency (FRA) and the Farmer Input Support Program (FISP). These two programs are responsible for purchasing maize at above-market prices and distributing subsidized fertilizer (Mason et al., 2011). These two agencies are responsible for coordinating significant amounts of inputs throughout the country prior to and during the growing season. For example, during the 2012/13 growing season approximately 180,000 metric tons of fertilizer were distributed to 900,000 farmers (Ricker-Gilbert et al., 2013). During this time crop yields have increased consistently, though analysis shows that favorable weather conditions likely contributed more significantly than agricultural inputs (Burke et al., 2010; Mason et al., 2011). This had the intended effect of price reduction for maize in four of Zambia's nine provincial capitals: Kabwe, Chipata, Lusaka, and Mongu though this is not a consistent trend across the country (Burke et al., 2010).

Despite these efforts, there has been no significant reduction to rural poverty levels since 2004 ( $77.3 \%$ to $76.6 \%$ ), but it is important to note that levels of stunting have decreased (Central Statistical Office, 2010, 2015; The World Bank, 2020). Though maize production increased $92 \%$, increasing household access to nutrition, on average per household, the net value added only a modest $20 \%$. Mason, et al. (2011) estimate that $58 \%-75 \%$ of the area harvest ratio increase can be directly attributed to weather patterns, a factor that cannot be relied on for long-term agricultural growth (Mason et al., 2011). Fertilizers may contribute as much as $36 \%$ of increased yield, but only $5 \%$ in total area of cultivation. Together this explains only $15 \%$ of growth as of 2011 . Further, it appears that larger farms (> 2 hectares) disproportionately benefit from these aid programs (Mason et al., 2011). Households that cultivated less than one hectare of land saw only $7 \%$ of the increase in total maize production. Efforts by both FRA 
and FISP may have inadvertently contributed to an increase in market prices of maize by up to $20 \%$ by fluctuating prices in the private sector, negatively affecting both urban and rural populations that must purchase maize outside the four capitals (Mason et al., 2011). This market instability has perhaps played a role in poverty levels remaining similar since 2004 (77.3\% to 76.6\%) (Central Statistical Office, 2010, 2015).

As a result of continued rural poverty, many organizations, both governmentally and non-governmentally funded, focus on directly targeting smallholder farmers for intervention. The funds from international agencies are often earmarked for specific purposes and cannot be allocated by the host country for alternative purposes. For example, total spending for The United States Agency for International Development (USAID) for sub-Sharan Africa in 2017 was 13 billion USD, with 418 million USD allocated specifically for Zambia (USAID, 2020). However, only 6 million USD focused on agricultural efforts. The majority of funding goes to HIV/AIDS treatment and prevention, with agriculture holding the eighth most funded category. Two of these USAID funded projects in Zambia are Integrating Gender and Nutrition within Agricultural Extension Services (INGENAES) and Production, Finance, and Improved Technology Plus (PROFIT+). The former seeks to reduce gender gaps in agricultural extension, promote empowerment of women farmers, and integrate nutrition with extension services. PROFIT + had several primary and related objectives. These were to improve the productivity of smallholder farms, increase the ability of smallholder farmers to access outside markets, and increase private sector investment in Eastern Province \& Lusaka.

\subsection{PROFIT+\& INGENAES}

To meet these three goals, PROFIT + held training workshops on agricultural 'best-practices', both in a classroom setting and in-person demonstrations at agricultural field sites. These demonstrations took place at 'demo-plots' so farmers could see the increased crop yields these practices gave. These practices consist of fertilizer/pesticide application, tilling techniques to reduce runoff and erosion, and storage methods to reduce mold growth. These harvest and post-harvest techniques serve to both increase crop yield and minimize loss to fungal blooms and pests. To achieve their second goal, PROFIT + funded the creation of Community Agrodealers (CADs) and established Lead Farmers (LFs). These CADs and LFs were all farmers in the villages surrounding Chipata township, selected to act as local leaders for the project. CADs were allocated funds to start agricultural supply shops in their communities. This would allow local farmers to access goods they would otherwise be unable to, as the distance to town and associated costs were, in many cases, extremely prohibitive. CADs further were to function as intermediaries between village farmers and outside markets, purchasing crops from farmers then reselling them, strengthening local agricultural-chains and reducing transportation costs. LFs were to act as information hubs for local farmers, answering questions concerning the workshops and teaching tools PROFIT + disseminated. They would often cultivate the demo-plots, leading the workshops.

Promoting gender equality was another component these trainings emphasized. Workshops focused on intrahousehold communication skills and tactics to promote equitable decision making and balanced power dynamics between men and women. The production of groundnuts was an important component of this. Women were encouraged to grow groundnuts to increase both economic power and social agency through direct access to economic markets (Farnworth et al., 2011). Groundnuts are particularly useful to households as they can be immediately eaten, stored for later use, processed into refined products, or sold. This provided not only a new source of revenue, but also served as a nutritional supplement to the household. This is particularly important as the stunting rates for children under five years of age is extremely high in Zambia. Stunting during childhood leaves these individuals susceptible to detrimental and long-term metabolic and cognitive impacts (Black et al., 2008; Crookston et al., 2011; Dewey \& Begum, 2011).

The third focus of these trainings sought to address practical issues faced by smallholder farmers, which differ significantly from large scale agriculture producers. In rural areas, smallholder farmers often have difficulty accessing many of the agricultural supplies necessary for stable crop production year to year. Materials for cultivation and storage are generally handmade and, in many cases, not weatherproof - a serious issue as eastern and southern Africa is experiencing increasingly variable weather patterns in the context of climate change (Harding, 2020; Makondo \& Thomas, 2020). Using local materials for storage, there is a constant risk of crop loss by insect damage, fungal contamination, floods- either during production or in post-production storage.

\subsection{Research Objectives}

The purpose of this study is to ascertain barriers, specifically related to market access and crop yields, faced by smallholder groundnut farmers in Eastern Zambia following implementation of the PROFIT+ program. 


\section{Background}

This research took place in Chipata District, Eastern Province during the fourth year of operation for PROFIT+ (2016). The research objective was to ascertain barriers smallholder farmers faced when trying to implement bestpractices taught by the organization. Using data collected from interviews and focus groups, four main barriers were identified that posed a serious risk to health and economic well-being. These include (a) exposure to aflatoxins by the Aspergillus fungus (b) exposure to pesticides due to a lack of personal protective equipment (PPE) (c) a lack of adequate storage facilities (d) issues related to climate change.

In tropical and subtropical regions of the world staple crops are at serious risk of contamination by Aspergillus fungi, and humans at risk from the carcinogenic metabolites they produce (specifically, Aspergillus flavus and Aspergillus parasiticus). Many areas of sub-Saharan Africa are at acute risk because Aspergillus thrives in staple crops (e.g., maize and groundnuts) that are improperly stored (Bankole et al., 2006; Hell \& Mutegi, 2011; Mupunga et al., 2017). Proper harvest procedures, and particularly post-harvest techniques, are necessary to ensure that crops remain free of aflatoxin producing fungi and do not pose a risk to humans or livestock. This primarily involved ensuring that no moisture is introduced to the stored crops during the rainy season and are kept pest-free.

Though agriculture only accounts for approximately $9 \%$ of Zambia's GDP, $62 \%$ of households own agricultural land (Central Statistical Office, 2015). Widespread subsistence farming, and farming for supplementary income, potentially exposes millions of Zambians to pesticides on a consistent basis. Farmers routinely purchase and apply pesticides; though, often without detailed knowledge of the specific chemicals they are using, the risks of certain classes of chemicals, or the PPE to prevent exposure. If mixed in improper concentrations, sprayed improperly, sprayed in inclement weather conditions, used without PPE, or stored incorrectly- these pesticides pose a significant hazard to farmer health both in the short and the long term (Kim et al., 2017). In some areas this issue may become more prevalent as the most consistent supplier of pesticides to farmers are multinational corporations that hire farmers to grow cash crops (e.g., cotton). These companies will often supply farmers with pesticides and sprayers, but not the protective equipment to ensure farmers are not themselves exposed.

\subsection{Study Site}

The Eastern Province of Zambia covers an area of 51,476 square miles, contains seven districts, and borders both Malawi and Mozambique. Chipata township is the provincial capital and has a population of approximately 450,000 people, three quarters of which reside in rural areas. This region has three seasons, a wet season from December-April, a cool dry season from May-August, and a hot dry season from September-November (this fieldwork took place during the cool, dry season post-harvest). The most common languages spoken in Eastern Province are Nyanja (Chewa), Nsenga, Nyanja, and Tumbuka. Eastern Province is one of the most rural, only 13.8\% of people in Eastern province live in an urban area and it relies significantly on agriculture for both home consumption and sale (Central Statistical Office, 2012).

Despite a heavy reliance on agriculture, stunting is relatively high in Eastern Province at 34\%, making it the fourth highest of ten provinces. The median age at first birth is 18.7 , and infant mortality rate is above the national average, averaging 97 deaths per 1,000 live births (Central Statistical Office, 2012). The most common cause of premature death is disease/illness at $75.7 \%$. Male children were at increased risk of dying in a group of under-five children with severe acute malnutrition (Central Statistical Office, 2012; Munthali et al., 2015). The largest proportion of men in the country with no education is in Eastern Province (13\%), and similarly the literacy rate is lowest at $54.4 \%$. The percentage of the population attending school at the age of five or older is $27.5 \%$ (Zambia Statistics Agency, 2019). When only primary school is included the percentage increases to $63.2 \%$. Women and men in this Province are least likely to report knowing methods for prevention of HIV, this lack of education additionally results in this region having the highest reporting rate for STIs (12\%) (Zambia Statistics Agency, 2019).

Table 1. Eastern province statistics

\begin{tabular}{llll}
\hline Population & & & \\
\hline Males & 784,680 & Sanitation & \\
Females & 807,981 & Improved & $39.2 \%$ \\
Total Population & $1,592,661$ & Unimproved & $44.5 \%$ \\
Median Age & 16.1 & Open Defecation & $16.3 \%$ \\
Growth Rate & $2.6 \%$ & & \\
\hline
\end{tabular}




\begin{tabular}{llll}
\hline Education (Women) & & Media Access & \\
None & $13.2 \%$ & Newspaper & $16.6 \%$ \\
Some Primary & $51.0 \%$ & Television & $19.0 \%$ \\
Completed Primary & $9.9 \%$ & Radio & $33.7 \%$ \\
Some Secondary & $19.5 \%$ & All Three & $3.6 \%$ \\
Completed Secondary & $3.5 \%$ & None & $51.6 \%$ \\
Higher & $2.9 \%$ & & \\
\hline
\end{tabular}

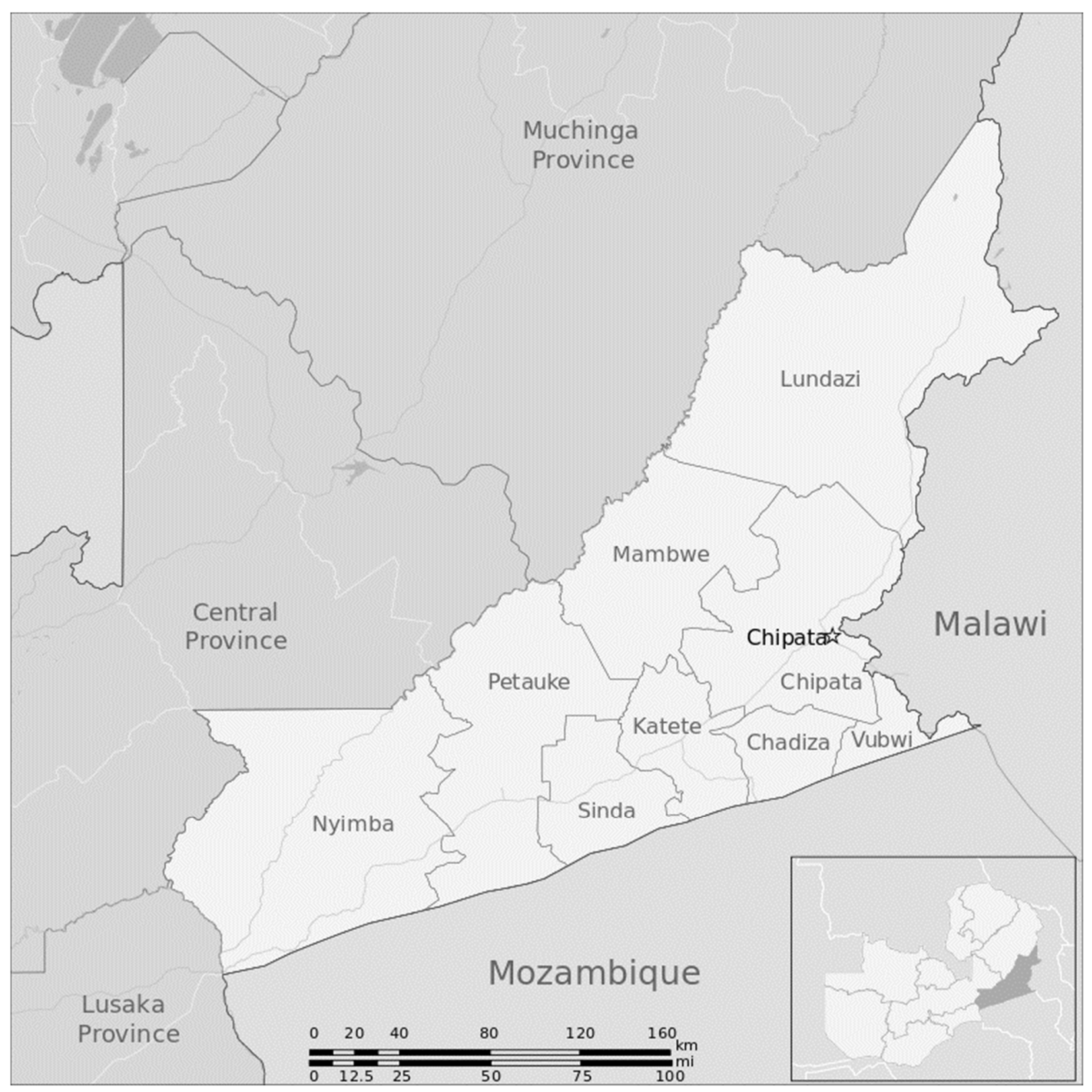

Figure 1. Map of Eastern Province, Zambia (Wikipedia, 2020)

\section{Methods}

Data for this project was collected July-August of 2016 through focus groups and individual semi-structured 
interviews. These assessed farmer knowledge of post-harvest practices and constraints to applying this knowledge. All interviews took place in the Chipata District with people from villages surrounding the township. Site selection overlapped with the region where PROFIT+ previously conducted trainings and workshops. All participants in this study were sampled through PROFIT + or Share Africa Zambia (SAZ, a Christian faith-based charity operation out of the United Kingdom). This study utilized a purposive sample to include male and female CADs, LFs, and farmers associated with SAZ who have participated in workshops. Focus group interviews included four groups of 3-6 men and women (focus groups included only members of the same gender to encourage equal participation). Following focus group discussions, sixteen semi-structured individual interviews took place. All interviews were conducted in Nyanja with the aid of a translator. Each interview lasted approximately one hour and each focus group one-and-one-half hours. Compensation was provided at the end of each interview and focus group (apart from two focus groups).

Table 2. Participant characteristics

\begin{tabular}{lclc}
\hline Participants Characteristics & & & \\
\hline Ages & Frequency (\%) & Sex & Frequency (\%) \\
$30-35$ & $2(12.5)$ & Male & $8(50 \%)$ \\
$36-40$ & $2(12.5)$ & Female & $8(50 \%)$ \\
$41-45$ & $1(6.25)$ & Marital Status & \\
$46-50$ & $5(31.25)$ & Single & $13(81.25)$ \\
$>50$ & $6(37.5)$ & Married & $2(12.5)$ \\
Education & & Divorced & $1(6.25)$ \\
Primary & $5(31.25)$ & & \\
Secondary & $11(68.75)$ & & \\
\hline
\end{tabular}

Focus group discussions took place before individual interviews to assess general knowledge concerning postharvest practices and to obtain information to further tailor individual interview questions. Focus group topics included information about allocation of labor at different stages of production, knowledge of post-harvest storage practices, knowledge and beliefs surrounding aflatoxins, use and access to pesticides and herbicides, use of other chemical inputs such as fertilizer, and intrahousehold decision making. Data on household allocation of labor, knowledge of best practices, and constraints to applying best practices were collected during individual semistructured interviews. Participants were asked who provided the most labor at each point in groundnut production, of special interest here is labor during harvest and post-harvest. Participants were then asked if they had attended any workshops pertaining to post-harvest storage techniques and, when they attended, and whom they then shared this information with (e.g., farmer field school or a demo-plot). Further, where they obtained much of the information about best storage practices. Data was gathered on what impeded farmers from applying their knowledge of storage techniques to mitigate aflatoxin contamination and increase usable yields. Participants were then asked if they had attended any workshops pertaining to pesticide safety, when they attended, and whom they then shared this information with (e.g., demo-plot meeting, with neighbors). Lastly, data was gathered on where they obtained most of the information about pesticide safety and what impeded farmers from applying their knowledge of safe pesticide use. Questions in individual interviews were kept broad and open-ended with data previously collected from focus groups used to probe to elicit additional information.

Descriptive statistics were calculated on basic demographic information and knowledge concerning both pesticides and aflatoxins. Interviews were then qualitatively analyzed for the presence of themes. Themes were identified from the focus groups and individual interviews by the authors (Dillon and Crosby). Quotes are taken from individual interviews to illustrate specific points made that are representative of the overall sentiments of smallholder farmers. Due to the small sample size of farmers interviewed we abstained from statistical tests to examine differences between gender, education level, etc.

\section{Results}

Of the issues faced by farmers that impacted their health and economic well-being, four general barriers/risks became more pronounced than others. These are lack of storage facilities, issues in aflatoxin identification, a lack of PPE while using pesticides, and issues of climate change. In some cases, these barriers may act as feedback 
loops, with health affecting economic productivity and vice versa.

Table 3. Pesticide and aflatoxin knowledge

\begin{tabular}{lclc}
\hline Pesticide & \multicolumn{3}{l}{ Aflatoxin } \\
\hline Information Received & Frequency (\%) & Information Received & Frequency (\%) \\
None & $3(18.75)$ & None & $2(12.5)$ \\
Workshops & $10(62.5)$ & Workshops & $9(56.25)$ \\
Monthly training & $3(18.75)$ & Monthly training & $1(6.25)$ \\
Constraints to safe use & & Missing & $4(25.0)$ \\
None & $4(25.0)$ & Identification & \\
Lack of chemicals/equipment & $6(37.5)$ & Change in plants & $6(37.5)$ \\
Damaged equipment & $3(18.75)$ & Change in seeds & $6(37.5)$ \\
Weather & $2(12.5)$ & Missing & $4(25)$ \\
Lack of knowledge & $1(6.25)$ & & \\
Pests & & & \\
Insects & $11(68.75)$ & & \\
Animals & $4(25.0)$ & & \\
Disease & $1(6.25)$ & & \\
\hline
\end{tabular}

One of the most reported barriers to implementing post-harvest practices was a lack of proper long-term storage facilities for keeping groundnuts. The two options available to smallholder farmers are homemade granaries (mudbrick and thatch) or $50 \mathrm{~kg}$ sacks stored inside the home, often in bedrooms or living areas. Home storage was a last resort as pests such as rats will eat groundnuts stored inside homes. Ideally, granaries are made of metal sheets for roofing and cement walls. Without access to these building materials, farmers in villages construct granaries using local materials (thatch and mudbrick). These roofs are much more susceptible to leaking on crops without the farmer's knowledge, increasing the moisture content of the groundnuts and dramatically increasing the likelihood any Aspergillus spores present in the crops will bloom. This, in turn, increases the probability of aflatoxin contamination. Informants knew of these risks but were largely unable to build granaries with metal roofs to prevent these issues.

Farmers knew the correct steps to decrease the risk of a fungal bloom (e.g., eliminate as much moisture as possible) but were far less able to identify aflatoxin contamination in groundnuts-reporting wide ranging physical characteristics to identify fungal contamination. These include weak/small looking plants, spots on seeds, whitish powder in the shells, and seeds having a bitter taste. Aflatoxins have no discernible taste and, unfortunately, often are not detectable through visual inspection alone. Thus, many of the indicators that farmers look for cannot adequately assess the presence or absence of these toxins. Further, Aspergillus is much more likely to grow in seeds with broken shells. Farmers are more likely to keep the broken/misshapen seeds for home consumption, as they cannot be sold in the market. Without knowing it, farmers may then be ingesting relatively high levels of aflatoxins. These compounds do not break down when subjected to heat, so cooking with and boiling the nuts does not reduce toxicity.

To supplement household income, many farmers work in neighbor's fields in exchange for cash payments. This necessitates the most vulnerable farmers leaving their crops in the field longer, increasing the risk of fungal contamination. Unpredictable rainfall patterns, exacerbated by climate change, stress groundnut plants, and, combined with the high ground temperatures that occur immediately before harvest, reduces the plants natural defenses against infection and increases the chances of contamination. Predation by insects further weakens plant resistance to fungal infections (Pitt et al., 2013). Further, unpredictable rains may soak groundnuts that are drying in fields and leak through the cracks in homemade granaries creating the moist environments in which Aspergillus thrives. During and post-harvest, visual inspection of crops is useful to remove any groundnuts obviously contaminated with fungus. However, as previously mentioned, visual inspection often fails to reveal the extent to which aflatoxins are present in crop yields and may lead individuals to believe they are unexposed when they are consuming relatively high levels of aflatoxins. 
If the farmer had groundnuts that were of lower quality, (after they already had enough stored for home consumption), shops in town would not buy them. These in turn would be sold to Malawi "suitcase" traders. These buyers cross the Malawi/Zambian border in the morning and visit smallholder farmers directly in their homes, offering to buy groundnuts from them. They offered much less money than the shops in town (2 kwacha per $\mathrm{kg}$ versus the 6-7 kwacha per $\mathrm{kg}$ in town shops). But, if the shops would not buy the farmers groundnuts, they often had no other recourse than to sell to these Malawian traders. If damaged nuts are being sold/processed across the border, the resulting products are more likely to be contaminated with aflatoxin. The potential for significant aflatoxin contamination through the informal economy is not trivial, as aflatoxin contamination in the region can be extremely high. The USDA threshold for human consumption of the aflatoxin B1 is $20 \mu \mathrm{g} / \mathrm{kg}$. A previous study in Chipata documented kernels with an average of $451 \mathrm{ppb}$, and milled nuts with an average of $547 \mathrm{ppb}$ (Njoroge et al., 2017). This is more than twenty times the limit considered safe for consumption in the United States.

Adults report using pesticides frequently and when asked only $25 \%$ reported that they had no constraints practicing best pesticide application practices. The remaining informants reported a variety of constraints, the most common of which being a lack of PPE. Full PPE includes gloves, gowns, shoe/head covers, masks/respirators, and face and eye protection. PPE in this area is prohibitively expensive and only available in Chipata township. It is often not feasible for households located in rural areas, most of which lack reliable access to transportation, to frequently visit town. Leaky sprayers, a commonly reported problem, soak the user in pesticides and compound a lack of PPE. As one informant succinctly phrased this, "that is not how life works in the village...so most people must adapt by wearing long sleeves, pants, and shoes [not sandals]. Most people in the village cannot afford PPE, and it is only sold in town, requiring more money for the trip." (Agness Phiri- all individual names reported in this article are pseudonyms to protect individual identity). Farmers stretch out supplies and equipment, continuing to use it even when it becomes dangerous. Such as the leaky sprayers that spill pesticides down farmers backs "...that burn like fire" and "... gives them a cough like the flu" (Mercy Banda).

When pesticides are available, the directions were exclusively in English or Kiswahili, not the local language Chinyanja. Many farmers, particularly those who completed only primary school, were unable to read the directions on the containers that the chemicals came in. A third barrier cited was the weather, as it was often prohibitive to pesticide use. Many pesticides require a moist ground to function most effectively, a rare occurrence during a drought year or the dry season. Conversely, during particularly rainy years pesticides are washed away into the water system if it rains after application. Many farmers reported being unable to use pesticides due to inclement weather conditions, some seasons effectively receiving no return for the economic investment into these chemicals. "Raining after pesticide application washes away the pesticides and wastes them" (Emily Mulenga).

When farmers stored groundnuts in the home, rats would frequently burrow inside the bags and eat them. To combat this, farmers would often mix pesticides in the bags with the groundnuts to prevent pests from preying on them before they could be sold or eaten by the household. This is particularly concerning because children frequently sneak peanuts straight from the bag to eat as snacks. Children are particularly susceptible to the effects of pesticides because they are undergoing rapid neurological development. Bags would be reused from previous years despite holes that allowed both pests and moisture inside.

\section{Discussion}

Smallholder groundnut farmers in the Chipata District have benefited from the efforts of PROFIT+ and there is optimism as the best practices espoused by this project have increased crop yields. However, challenges remain, and farmers expressed frustration with their inability to access supplies and technologies that would make their work more productive and safer. These frustrations at the lack of opportunity, and uncertainty towards the future, echo fundamental underlying themes that public health and development faces in the coming years.

\subsection{Issues with Aflatoxins}

Aflatoxins are difuranocoumarin compounds produced by the fungal Aspergillus family. The most toxic of which, $\mathrm{B} 1$ (AFB1), is one of the most potent known naturally occurring hepatocarcinogens (Do \& Choi, 2007). Ingestion of high levels of aflatoxins can result in an acute condition known as aflatoxicosis. These exposures are particularly dangerous and cause severe liver damage that can lead to death (Lewis et al., 2005). Adults exhibit relatively high tolerance to acute aflatoxin exposure; however, children do not have the same tolerance and are usually the victims of fatal poisonings (Williams et al., 2004). However, adults are at risk of liver complications if they are infected with the Hepatitis B or C virus (HBV and HCV). The relative risk of developing hepatocellular carcinoma increases from five to sixty times when aflatoxin exposure cooccurs with HBV infection (Henry et al., 2002). In addition to liver damage, these compounds are implicated in stunting of children under five and possess immunosuppressant properties (Liu \& Wu, 2010; Williams et al., 2004; Wu et al., 2007). Aflatoxins influence on child stunting is 
particularly worrying as they may exacerbate the stunting epidemic present at extremely high levels in Zambia (approximately 40\%) (The World Bank, 2020). This represents a serious and significant public health concern as the effects from stunting impacts both long- and short-term health (Dewey \& Begum, 2011). Giving the prevalence of stunting throughout sub-Saharan Africa (151 million children) this work has the potential to offer critical implications far beyond the research location (UNICEF, 2018).

In recent years, groundnuts and other ready-to-use therapeutic foods have received more attention as the focus of development efforts confront the issue of child stunting and undernutrition (Schoonees et al., 2013). However, proper storage of groundnuts to prevent Aspergillus blooms is consistently a challenge (Waliyar et al., 2015). As groundnuts are commonly thought of as a 'women's crop', it is primarily women involved in cultivating and processing harvested groundnuts, though the commercialization of groundnuts may change this in the future (Orr et al., 2014). This can result in both multiple pathways and higher exposure levels for women during harvest, processing, and consumption. As a result, nutrition efforts may have the unintended consequence of increasing female and child exposure to aflatoxins in contaminated groundnuts.

\subsection{Issues with Pesticides}

Smallholder farmers and their families are vulnerable to pesticide exposure through multiple pathways. These pathways are divided into four main routes: occupational, paraoccupational, environmental, and residential (Deziel et al., 2015). Occupational exposure occurs during the application of pesticides directly onto crops or stored grain/seed. This exposure route only affects those directly involved in application or those working in the area immediately post-application. Paraoccupational exposure occurs when farmers bring pesticide residues into the home on their clothes or other equipment used in the application process. If a farmer does not remove his or her clothing outside and wash it separately, the rest of the household is at an increased risk of contact with active pesticides. Pesticides that enter the household pose a particular risk because they do not degrade as quickly when not exposed to direct UV light, moisture, microorganisms, etc. This increases the odds a person living in the house will be exposed (Bradman et al., 2007; Deziel et al., 2015; Quandt et al., 2004). Environmental exposure poses a risk for all those living close to an area where pesticides are applied. Wind and runoff water, particularly near streams and other surface water bodies, can carry the pesticides away from their application site to surrounding households and communities (Arcury et al., 2007; Lu et al., 2000). Lastly, residential exposure refers to pesticides applied immediately surrounding or inside the home (Deziel et al., 2015). Often grain or seed is stored in the home of farmers and coated with pesticides to keep pests from eating them. This is particularly worrying for children, as they will commonly snack on sprayed groundnuts stored within the home. Similarly, some report storing water for drinking in old pesticide containers - one participant punched holes in his used pesticide containers that would prevent neighbors from using discarded canisters in this manner.

Pesticides act as endocrine disruptors in humans, altering normal hormone function (Mnif et al., 2011). As a result, these chemicals affect men, women, and children differently. Many organophosphates and organochlorines are estrogenic and bind to estrogen and androgen receptors, altering levels of sex hormones leading to dysfunction (Taxvig et al., 2013). Decreased sperm count/quality and impaired reproductive function is associated with pesticide exposed males (Figà - Talamanca et al., 2001). Every year of work by men using pesticides is associated with a steady and significant drop in testosterone levels (Abell et al., 2000). Female reproduction is particularly susceptible to dysregulation by estrogenic compounds as slight hormone imbalances may result in impairments to fertility and menstruation (Nicolopoulou-Stamati \& Pitsos, 2001). During pregnancy pesticides also act as abortifacients and teratogens, increasing the likelihood of spontaneous abortion (Bretveld et al., 2006; Petrelli et al., 2003). If pregnancy does continue, exposure significantly elevates the risk of congenital birth defects (Bell et al., 2001; Calvert et al., 2007). Lastly, children are at risk of neurodevelopment and behavioral impairment that may persist throughout the life course (Guillette et al., 1998; Roberts et al., 2012). These impairments were wide ranging including motor deficits, attention deficit and hyperactivity disorders, and decreased IQ to name a few (Engel et al., 2011; Rauh et al., 2006; Young et al., 2005). Signs and symptoms of acute pesticide poisoning are often difficult to diagnose and are dependent on the class of chemical used. For example, phosphonate pesticides can cause pneumonia-like symptoms, while the effects of organochlorines range from tremors and ataxia to acute seizures (Roberts et al., 2012).

It was clear that farmers knew some correct methods for minimizing occupational exposure to pesticides during application; however, the majority did not have access to PPE or sprayers that did not leak. Residential or environmental pathways of exposure were rarely mentioned in relation to health. Farmers cited weather as a barrier for pesticide application but did not indicate that runoff or wind could cause exposure to those not in the field. Potentially dangerous storage practices, such as the use of pesticide in groundnut storage bags or leaving food out in the home laced with rat poison, were common. This practice may keep the crop safe from pests, but with children 
frequently snacking on the bagged groundnuts, they face dangerous exposure to these chemicals both orally and dermally. In the villages, clothes are washed by hand, leading to potential dermal exposure every time clothes worn during pesticide application are cleaned. Further, a lack of differentiation, and distance, between "washing" water and drinking water could contribute to contamination. Household chores such as these are frequently are done by women and younger household members, opening them to the biological effects of pesticides mentioned previously (Phiri, 2016).

Both pesticides and aflatoxins possess properties which can impact individuals both during growth and development into adulthood. This includes both pre- and post-natal exposures - an important consideration given the high reproductive rate of Zambia and the proportion of women engaged in agricultural tasks (Johnson et al., 2017). Over the lifespan of an individual, exposure to environmental toxicants poses serious economic concerns at the micro and macro level. The disability-adjusted life years (DALYs) associated with environmental exposures in the global south significantly impacts productivity. DALYs are a measure of overall disease burden and specifically time lost as a result of ill health of disability. It is a more accurate measure, in some ways, of disease burden in a population as opposed to life expectancy. Not only does exposure to environmental toxins and toxicants lead to population level morbidity that further taxes healthcare systems but causes considerable economic loss. A critical stance needs to be taken to assess that there are not populations being put at undo risk with interventions like this. There is evidence that ingestion of aflatoxins not only causes damage to the liver but can cause inflammation in the intestinal lining (Maresca \& Fantini, 2010). This inflammation limits nutrient absorption, making the results of the intervention relatively less effective in areas where aspergillus is endemic.

\subsection{Lack of Transparency with Training Materials}

Across development programs and projects launched in developing countries, training materials given to participants are not typically available or easy to access by third parties. Training programs and specific goals, timelines, and reporting on outcomes are more commonly available types of data. In 2014 USAID released an update to their stance on development data to increase transparency and openness (USAID, 2019). While this is an excellent start, training materials given to those participating in USAID funded programs are not included in this (note this refers to materials participants receive, trainings that USAID provides employees and volunteers is available). It would be useful both for transparency and for future research to have materials publicly available and more importantly, easily accessible. Enabling access to these materials would allow for a more thorough examination as to what formats and content of trainings materials are most efficacious in each context. Further, it allows the opportunity for a more formal examination and evaluation of materials between agencies and programs by researchers. PROFIT + follows this trend and the training materials are not available (that the authors are able to find) online in any format. As such a formal analysis of these texts are unable to be completed at this time.

\subsection{Eastern/Southern Africa and Climate Change}

"A big challenge we face is from climate change and drought" (Anna Chirwa). Climate change and instability threatens this project and others that focus on agriculture in Zambia, and all southern and eastern Africa. The basis of this intervention relies on the assumption that there is (1) arable land and (2) predictable weather patterns to successfully cultivate groundnut crops free of fungal contamination. The weather patterns experienced in 20182019 raise serious doubt that conditions will continue in a predictable manner conducive to agricultural interventions. The most severe drought in a century struck southern Zambia (and surrounding countries such as Zimbabwe) extremely hard(Harding, 2020). Maize crops, particularly in the southern areas of Zambia, were largely killed and left more than 2 million people in need of food aid. Further complicating this issue is the reliance on hydroelectric power from the Kariba dam, located on the Zambezi river. Drought years lead to electricity shortages and greater difficulty storing clean food and water. People all around the country are aware of the threats of climate change and discuss how the weather patterns have shifted from the previous decades (Nyanga et al., 2011).

All of southern and eastern Africa has been experiencing a general warming trend over the past few decades, leading to significant alterations in the hydrological cycle (Kusangaya et al., 2014; New et al., 2006). This results in both an increase in rainfall variability and a decrease in the total amount of rainfall in the region generally (Mazvimavi, 2010; Ngongondo et al., 2011). However, more research is needed in this region as data on climate change and warming trends is largely gathered in the Global North where infrastructure and technological capacity are both high(Mouton et al., 2008). These changes place smallholder farmers at particular risk as there is not the infrastructure or capital to irrigate with secondary water sources. Inputs and practices espoused by agricultural programs likely need to be tailored to specific locations to maximize efficiency, rather than a one-size-fits-all model of uniform inputs (e.g., nitrogen fertilizer). This along with access to crops besides maize which can be eaten in the home and grown year-round and are resistant to drought (Droppelmann et al., 2017). Drought tolerant 
crops are a focal point of many efforts, specifically maize, the staple crop across many areas of both eastern and southern Africa (Fisher et al., 2015). In addition to modified crops, there is a movement towards a return to neglected or underutilized crops that grow traditionally in these regions but are not as commonly grown or eaten in favor of maize. These include taro, wild melon, and amaranth species to name a few (Chivenge et al., 2015). These rely on either the availability of seeds for drought-tolerant or a cultural shift towards these underutilized, but locally available plant varietals.

\subsection{Limitations}

It is important to note that the farmers interviewed for this research were chosen by PROFIT + . This purposive selection may bias the results of these findings in favor of the organization. Additionally, each participant was interviewed once, limiting time available to build rapport, which may have altered responses (Bernard, 2017).

\section{Conclusion}

This study, conducted in the Eastern Province of Zambia, highlights several barriers that groundnut farmers face with market access and improving crop yields, including the increased risk of environmental exposure to toxins due to lack of PPE and insufficient storage facilities. These risks and barriers faced by smallholder farmers are not discrete, isolated problems. Rather, they result from changes in agricultural management, influenced by international organizations, and poverty in a setting of climatic instability.

Smallholder farmers in Eastern Province identify tangible benefits gained through international programs such as PROFIT + , but barriers remain that place significant portions of the population at risk to detrimental environmental exposures. Inputs and practices espoused by agricultural programs need to be tailored to specific locations to maximize efficacy rather than a one-size-fits-all model of uniform inputs (e.g., nitrogen fertilizer) and their downstream effects. In Eastern Zambia, increases in crop yields without market demand or access to a stable market leaves farmers with excess groundnuts that must be stored in a sealed, low-humidity environment to reduce the risk of contamination and loss by pests and fungus. However, limited resources in rural areas of Eastern Province pose a barrier for farmers trying to build proper long-term storage. Unpredictable weather patterns exacerbate issues with storage and increase the risk of crop contamination and lower the value of the crop. Shops are less likely to buy low-quality groundnuts, increasing the chance that households will sell them to Malawian traders to recoup financial losses.

Access to protective equipment and eliminating the proliferation of the aspergillus fungus are two critical measures to increase smallholder Zambian farmer health and economic well-being. Lack of proper storage facilities means that the household is more likely to consume crops contaminated with aflatoxin, posing a serious risk to child growth and long-term health for adults. Improper pesticide use and lack of PPE for pesticide application also contribute to the risk for poor health outcomes for farmers and household members in Eastern Province. Lack of information on proper pesticide application and limited PPE increase the risk of pesticide exposure for farmers and their families. For example, farmers will mix pesticides in the bags of groundnuts to prevent pest contamination, increasing the risk of household exposure when children sneak groundnuts from storage. Childhood exposure to pesticides is an important health risk because of their effect on neurological and cognitive development. Exposure to these human-made toxicants and naturally occurring toxins impact health in both the long and short term, potentially affecting lifetime economic productivity, further reinforcing a cycle of poverty in these rural areas.

\section{References}

Abell, A., Ernst, E., \& Bonde, J. P. (2000). Semen quality and sexual hormones in greenhouse workers. Scandanavian Journal of Work, Environment \& Health, 26(6), 492-500.

Alene, A. D., \& Coulibaly, O. (2009). The impact of agricultural research on productivity and poverty in subSaharan Africa. Food Policy, 34(2), 198-209. https://doi.org/10.1016/j.foodpol.2008.10.014

Arcury, T. A., Grzywacz, J. G., Barr, D. B., Tapia, J., Chen, H., \& Quandt, S. A. (2007). Pesticide urinary metabolite levels of children in Eastern North Carolina farmworkers households. Environmental Health Perspectives, 115(8), 1254-1260. https://doi.org/10.1289/ehp.9975

Bankole, S., Schollenberger, M., \& Drochner, W. (2006). Mycotoxins in food systems in Sub Saharan Africa: A review. Mycotoxin Research, 22(3), 163-169. https://doi.org/10.1007/BF02959270

Bell, E. M., Hertz-picciotto, I., \& Beaumont, J. J. (2001). A Case-Control Study of Pesticides and Fetal Death Due to Congenital Anomalies. Epidemiology, 12(2), 148-156.

Bernard, H. R. (2017). Research methods in anthropology: Qualitative and quantitative approaches. Rowman \& Littlefield. Retrieved from www.altamirapress.com 
Black, R. E., Allen, L. H., Bhutta, Z. A., Caulfield, L. E., de Onis, M., Ezzati, M., Mathers, C., \& Rivera, J. (2008). Maternal and child undernutrition: global and regional exposures and health consequences. The Lancet, 371(9608), 243-260. https://doi.org/10.1016/S0140-6736(07)61690-0

Bradman, A., Whitaker, D., Quirós, L., Castorina, R., Henn, B. C., Nishioka, M., Morgan, J., Barr, D. B., Harnly, M., Brisbin, J. A., Sheldon, L. S., McKone, T. E., \& Eskenazi, B. (2007). Pesticides and their metabolites in the homes and urine of farmworker children living in the Salinas Valley, CA. Journal of Exposure Science and Environmental Epidemiology, 17(4), 331-349. https://doi.org/10.1038/sj.jes.7500507

Bretveld, R. W., Thomas, C. M. G., Scheepers, P. T. J., Zielhuis, G. A., \& Roeleveld, N. (2006). Pesticide exposure: The hormonal function of the female reproductive system disrupted? Reproductive Biology and Endocrinology, 4, 1-14. https://doi.org/10.1186/1477-7827-4-30

Burke, W. J., Jayne, T. S., \& Chapoto, A. (2010). Factors Contributing to Zambia's 2010 Maize Bumper Harvest. In Food Security Research Project (Vol. 2010, Issue 48).

Calvert, G. M., Alarcon, W. A., Chelminski, A., Crowley, M. S., Barrett, R., Correa, A., Higgins, S., Leon, H. L., Correia, J., Becker, A., Allen, R. H., \& Evans, E. (2007). Case report: Three farmworkers who gave birth to infants with birth defects closely grouped in time and place - Florida and North Carolina, 2004-2005. Environmental Health Perspectives, 115(5), 787-791. https://doi.org/10.1289/ehp.9647

Central Statistical Office. (2010). 2010 Census of Population and Housing: National Analytical Report.

Central Statistical Office. (2012). Zambia 2010 Census of Population and Housing National Analytic Report. Retrieved from www.zamstats.gov.zm

Central Statistical Office. (2015). Zambia Demographic and Health Survey 2013-14.

Chivenge, P., Mabhaudhi, T., Modi, A. T., \& Mafongoya, P. (2015). The potential role of neglected and underutilised crop species as future crops under water scarce conditions in Sub-Saharan Africa. International Journal of Environmental Research and Public Health, 12(6), 5685-5711. https://doi.org/10.3390/ijerph120605685

Crookston, B. T., Dearden, K. A., Alder, S. C., Porucznik, C. A., Stanford, J. B., Merrill, R. M., Dickerson, T. T., $\&$ Penny, M. E. (2011). Impact of early and concurrent stunting on cognition. Maternal and Child Nutrition, 7(4), 397-409. https://doi.org/10.1111/j.1740-8709.2010.00255.x

Dewey, K. G., \& Begum, K. (2011). Long-term consequences of stunting in early life. Maternal and Child Nutrition, 7(SUPPL. 3), 5-18. https://doi.org/10.1111/j.1740-8709.2011.00349.x

Deziel, N. C., Friesen, M. C., Hoppin, J. A., Hines, C. J., Thomas, K., \& Beane Freeman, L. E. (2015). A Review of Nonoccupational Pathways for Pesticide Exposure in Women Living in Agricultural Areas. Environmental Health Perspectives, 123(6), 515-524. https://doi.org/10.1289/ehp.1408273

Do, J. H., \& Choi, D.-K. (2007). Aflatoxins : Detection, Toxicity, and Biosynthesis. Biotechnology and Bioprocess Engineering, 12, 585-593.

Droppelmann, K. J., Snapp, S. S., \& Waddington, S. R. (2017). Sustainable intensification options for smallholder maize-based farming systems in sub-Saharan Africa. Food Security, 9(1), 133-150. https://doi.org/10.1007/s12571-016-0636-0

Engel, S. M., Wetmur, J., Chen, J., Zhu, C., Barr, D. B., Canfield, R. L., \& Wolff, M. S. (2011). Prenatal exposure to organophosphates, paraoxonase 1, and cognitive development in childhood. Environmental Health Perspectives, 119(8), 1182-1188. https://doi.org/10.1289/ehp.1003183

Farnworth, C., Akamandisa, V., \& Hichaambwa, M. (2011). Zambia Feed the Future Gender Assessment. Retrieved

from http://www.pandiawarleggan.com/pdf/GenderandValueChainStudyforUSAIDZambia2011.pdf

Figà - Talamanca, I., Traina, M. E., \& Urbani, E. (2001). Occupational exposures to metals, solvents and pesticides: Recent evidence on male reproductive effects and biological markers. Occupational Medicine, 51(3), 174 188. https://doi.org/10.1093/occmed/51.3.174

Fisher, M., Abate, T., Lunduka, R. W., Asnake, W., Alemayehu, Y., \& Madulu, R. B. (2015). Drought tolerant maize for farmer adaptation to drought in sub-Saharan Africa: Determinants of adoption in eastern and southern Africa. Climatic Change, 133(2), 283-299. https://doi.org/10.1007/s10584-015-1459-2

Guillette, E. A., Meza, M. M., Aquilar, M. G., Soto, A. D., \& Garcia, I. E. (1998). An anthropological approach to 
the evaluation of preschool children exposed to pesticides in Mexico. Environmental Health Perspectives, 106(6), 347-353. https://doi.org/10.1289/ehp.98106347

Harding, A. (2020). Climate change has brought parts of Zambia to the brink of famine. BBC News. https://www.bbc.com/news/av/world-africa-50976829

Hell, K., \& Mutegi, C. (2011). Aflatoxin control and prevention strategies in key crops of Sub-Saharan Africa. African Journal of Microbiology Research, 5(5), 459-466. https://doi.org/10.5897/AJMR10.009

Henry, S. H., Bosch, F. X., \& Bowers, J. C. (2002). Aflatoxin, hepatitis and worldwide liver cancer risks. In Mycotoxins and Food Safety (pp. 229-233). Springer, Boston, MA. https://doi.org/10.1007/978-1-46150629-4_24

Jayne, T. S., \& Rashid, S. (2013). Input subsidy programs in sub-Saharan Africa: A synthesis of recent evidence. Agricultural Economics (United Kingdom), 44(6), 547-562. https://doi.org/10.1111/agec.12073

Johnson, C. H., Athersuch, T. J., Collman, G. W., Dhungana, S., Grant, D. F., Jones, D. P., Patel, C. J., \& Vasiliou, V. (2017). Yale school of public health symposium on lifetime exposures and human health: The exposome; Summary and future reflections. Human Genomics, 11(1), 1-8. https://doi.org/10.1186/s40246-017-0128-0

Kim, K. H., Kabir, E., \& Jahan, S. A. (2017). Exposure to pesticides and the associated human health effects. Science of the Total Environment, 575, 525-535. https://doi.org/10.1016/j.scitotenv.2016.09.009

Kusangaya, S., Warburton, M. L., Archer van Garderen, E., \& Jewitt, G. P. W. (2014). Impacts of climate change on water resources in southern Africa: A review. Physics and Chemistry of the Earth, 67-69, 47-54. https://doi.org/10.1016/j.pce.2013.09.014

Lewis, L., Onsongo, M., Njapau, H., Schurz-Rogers, H., Luber, G., Kieszak, S., Nyamongo, J., Backer, L., Dahiye, A. M., Misore, A., DeCock, K., Rubin, C., Nyikal, J., Njuguna, C., Langat, A., Kilei, I. K., Tetteh, C., Likimani, S., Oduor, J., ... Gupta, N. (2005). Aflatoxin contamination of commercial maize products during an outbreak of acute aflatoxicosis in eastern and central Kenya. Environmental Health Perspectives, 113(12), 1763-1767. https://doi.org/10.1289/ehp.7998

Liu, Y., \& Wu, F. (2010). Global burden of Aflatoxin-induced hepatocellular carcinoma: A risk assessment. Environmental Health Perspectives, 118(6), 818-824. https://doi.org/10.1289/ehp.0901388

Lu, C., Fenske, R. A., Simcox, N. J., \& Kalman, D. (2000). Pesticide Exposure of Children in an Agricultural Community: Evidence of Household Proximity to Farmland and Take Home Exposure Pathways. Environmental Research, 84(3), 290-302. https://doi.org/10.1006/enrs.2000.4076

Makondo, C. C., \& Thomas, D. S. G. (2020). Seasonal and intra-seasonal rainfall and drought characteristics as indicators of climate change and variability in Southern Africa: a focus on Kabwe and Livingstone in Zambia. Theoretical and Applied Climatology, 140(1-2), 271-284. https://doi.org/10.1007/s00704-019-03029-x

Maresca, M., \& Fantini, J. (2010). Some food-associated mycotoxins as potential risk factors in humans predisposed to chronic intestinal inflammatory diseases. Toxicon, 56(3), 282-294. https://doi.org/10.1016/j.toxicon.2010.04.016

Mason, N. M., Burke, W. J., Shipekesa, A., \& Jayne, T. S. (2011). The 2011 Surplus in Smallholder Maize Production in Zambia: Drivers, Beneficiaries, and Implications for Agricultural and Poverty Reduction Policies (Vol. 58).

Mazvimavi, D. (2010). Investigating changes over time of annual rainfall in Zimbabwe. Hydrology and Earth System Sciences, 14(12), 2671-2679. https://doi.org/10.5194/hess-14-2671-2010

Mnif, W., Hassine, A. I. H., Bouaziz, A., Bartegi, A., Thomas, O., \& Roig, B. (2011). Effect of endocrine disruptor pesticides: A review. International Journal of Environmental Research and Public Health, 8(6), 2265-2303. https://doi.org/10.3390/ijerph8062265

Mouton, J., Boshoff, N., De Waal, L., Esau, S., \& Van Niekerk, D. (2008). The State of Public Science in the SADC Region. In Towards a Common Future: Higher Education in the SADC Region (pp. 197-302). Retrieved from http://www.sarua.org/?q=content/chapter-4-state-public-science-sadc-region

Munthali, T., Jacobs, C., Sitali, L., Dambe, R., \& Michelo, C. (2015). Mortality and morbidity patterns in underfive children with severe acute malnutrition (SAM) in Zambia: A five-year retrospective review of hospitalbased records (2009-2013). Archives of Public Health, 73(1), 1-9. https://doi.org/10.1186/s13690-015-00721 
Mupunga, I., Mngqawa, P., \& Katerere, D. R. (2017). Peanuts, aflatoxins and undernutrition in children in SubSaharan Africa. Nutrients, 9(12), 1-12. https://doi.org/10.3390/nu9121287

New, M., Hewitson, B., Stephenson, D. B., Tsiga, A., Kruger, A., Manhique, A., Gomez, B., Coelho, C. A. S., Masisi, D. N., Kululanga, E., Mbambalala, E., Adesina, F., Saleh, H., Kanyanga, J., Adosi, J., Bulane, L., Fortunata, L., Mdoka, M. L., \& Lajoie, R. (2006). Evidence of trends in daily climate extremes over southern and west Africa. J. Geophys. Res, 111, 14102. https://doi.org/10.1029/2005JD006289

Ngongondo, C., Xu, C. Y., Gottschalk, L., \& Alemaw, B. (2011). Evaluation of spatial and temporal characteristics of rainfall in Malawi: A case of data scarce region. Theoretical and Applied Climatology, 106(1-2), 79-93. https://doi.org/10.1007/s00704-011-0413-0

Nicolopoulou-Stamati, P., \& Pitsos, M. A. (2001). The impact of endocrine disrupters on the female reproductive system. Human Reproduction Update, 7(3), 323-330.

Njoroge, S. M. C., Matumba, L., Kanenga, K., Siambi, M., Waliyar, F., Maruwo, J., Machinjiri, N., \& Monyo, E. S. (2017). Aflatoxin B1 levels in groundnut products from local markets in Zambia. Mycotoxin Research, 33(2), 113-119. https://doi.org/10.1007/s12550-017-0270-5

Nyanga, P. H., Johnsen, F. H., Aune, J. B., \& Kalinda, T. H. (2011). Smallholder Farmers' Perceptions of Climate Change and Conservation Agriculture: Evidence from Zambia. Journal of Sustainable Development, 4(4), 73-85. https://doi.org/10.5539/jsd.v4n4p73

Orr, A., Tsusaka, T., \& Kee-Tui, S. (2014). Gender tools for value chain analysis: Examples from groundnuts in Eastern Province, Zambia. In ICRISAT Socioeconomic Discussion Paper Series (Issue 21). Retrieved from http://oar.icrisat.org/8275/

Petrelli, G., Figà-Talamanca, I., Lauria, L., \& Mantovani, A. (2003). Spontaneous abortion in spouses of greenhouse workers exposed to pesticides. Environmental Health and Preventive Medicine, 8(3), 77-81. https://doi.org/10.1007/BF02897919

Phiri, D. T. (2016). Rural children's role in buffering household poverty through ganyu (piecework) in Zambia. Children's Geographies, 14(6), 685-700. https://doi.org/10.1080/14733285.2016.1163326

Pitt, J. I., Taniwaki, M. H., \& Cole, M. B. (2013). Mycotoxin production in major crops as influenced by growing, harvesting, storage and processing, with emphasis on the achievement of Food Safety Objectives. Food Control, 32(1), 205-215. https://doi.org/10.1016/j.foodcont.2012.11.023

Quandt, S. A., Arcury, T. A., Rao, P., Snively, B. M., Camman, D. E., Doran, A. M., Yau, A. Y., Hoppin, J. A., \& Jackson, D. S. (2004). Agricultural and residential pesticides in wipe samples from farmworker family residences in North Carolina and Virginia. Environmental Health Perspectives, 112(3), 382-387. https://doi.org/10.1289/ehp.6554

Rauh, V., Garfinkel, R., Perera, F. P., Andrews, H., Hoepner, L., Barr, D. B., Whitehead, R., Tang, D., \& Whyatt, R. M. (2006). Impact of Prenatal Chlorpyrifos Exposure on Neurodevelopment in the First 3 Years of Life Among Inner-City Children. Pediatrics, 118(6), e1845-e1859. https://doi.org/10.1542/peds.20060338.Impact

Ricker-Gilbert, J., Mason, N. M., Darko, F. A., \& Tembo, S. T. (2013). What are the effects of input subsidy programs on maize prices? Evidence from Malawi and Zambia. Agricultural Economics, 44(6), 671-686. https://doi.org/10.1111/agec.12081

Roberts, J., Karr, C., \& Council on Environmental Health. (2012). Pesticide Exposure in Children James. Pediatrics, 130(6), e1765-e1788. https://doi.org/10.1542/peds.2012-2758.Pesticide

Schoonees, A., Lombard, M., Musekiwa, A., Nel, E., \& Volmink, J. (2013). Ready-to-use therapeutic food for home-based treatment of severe acute malnutrition in children from six months to five years of age ( Review ) SUMMARY OF FINDINGS FOR THE MAIN COMPARISON. Cochrane, 6. https://doi.org/10.1002/14651858.CD009000.pub2.www.cochranelibrary.com

Taxvig, C., Hadrup, N., Boberg, J., Axelstad, M., Bossi, R., Bonefeld-Jørgensen, E. C., \& Vinggaard, A. M. (2013). In vitro - in vivo correlations for endocrine activity of a mixture of currently used pesticides. Toxicology and Applied Pharmacology, 272(3), 757-766. https://doi.org/10.1016/j.taap.2013.07.028

The World Bank. (2020). Prevalence of stunting, height for age (\% of children under 5) - Zambia. Retrieved from https://data.worldbank.org/indicator/SH.STA.STNT.ZS?locations $=$ ZM

UNICEF. (2018). Levels and Trends in Child Malnutrition: UNICEF/WHO/World Bank Group Joint Child 
Malnutrition Estimates.

USAID. (2019). Our Commitment to Transparency $\mid$ Results \& Data $\mid$ U.S. Agency for International Development. Retrieved from https://www.usaid.gov/results-and-data/progress-data/transparency

USAID. (2020). United States Agency for International Development- FAE: Dashboard. Retrieved from https://explorer.usaid.gov/

Waliyar, F., Osiru, M., Ntare, B. R., Vijay Krishna Kumar, K., Sudini, H., Traore, A., \& Diarra, B. (2015). Postharvest management of aflatoxin contamination in groundnut. World Mycotoxin Journal, 8(2), 245-252. https://doi.org/10.3920/WMJ2014.1766

Wikipedia. (2020). Eastern Province, Zambia. Retrieved from https://en.wikipedia.org/wiki/Eastern_Province,_Zambia\#/media/File:Zambia_Eastern_Province_Districts.s $\mathrm{vg}$

Williams, J. H., Phillips, T. D., Jolly, P. E., Stiles, J. K., Jolly, C. M., \& Aggarwal, D. (2004). Human aflatoxicosis in developing countries: A review of toxicology, exposure, potential health consequences, and interventions. American Journal of Clinical Nutrition, 80(5), 1106-1122. https://doi.org/10.1093/ajen/80.5.1106

Wu, H. C., Wang, Q., Wang, L. W., Yang, H. I., Ahsan, H., Tsai, W. Y., Wang, L. Y., Chen, S. Y., Chen, C. J., \& Santella, R. M. (2007). Polycyclic aromatic hydrocarbon- and aflatoxin-albumin adducts, hepatitis B virus infection and hepatocellular carcinoma in Taiwan. Cancer Letters, 252(1), 104-114. https://doi.org/10.1016/j.canlet.2006.12.010

Young, J. G., Eskenazi, B., Gladstone, E. A., Bradman, A., Pedersen, L., Johnson, C., Barr, D. B., Furlong, C. E., \& Holland, N. T. (2005). Association between in utero organophosphate pesticide exposure and abnormal reflexes in neonates. NeuroToxicology, 26(2), 199-209. https://doi.org/10.1016/j.neuro.2004.10.004

Zambia Statistics Agency. (2019). Zambia Demographic and Health Survey 2018. Retrieved from www.DHSprogram.com

\section{Copyrights}

Copyright for this article is retained by the author(s), with first publication rights granted to the journal.

This is an open-access article distributed under the terms and conditions of the Creative Commons Attribution license (http://creativecommons.org/licenses/by/4.0/). 